\title{
Direct nodal sampling by echoendoscopy in lung cancer: the clinician's expectations
}

\author{
Direct nodal sampling by echoendoscopy in lung cancer
}

\author{
Maren Schuhmann • Ralf Eberhardt • Felix J. F. Herth
}

Received: 6 June 2010 /Revised: 1 November 2010 /Accepted: 9 December 2010 /Published online: 15 January 2011

(C) European Society of Radiology 2011

\begin{abstract}
Background Mediastinal lymph node staging for lung cancer remains one of the most important factors to determine patient outcome.

Methods Noninvasive imaging techniques such as CT, MRI, PET and PET-CT provide some answers but no tissue diagnosis. Results The development of endo-oesophageal (EUS) and endobronchial ultrasound (EBUS) with fine-needle aspiration has provided the clinician with a tool to investigate the mediastinum and the adrenal gland with a safe, minimally invasive procedure that can be performed on an outpatient basis. Conclusion The aim of this article was to give radiologists an overview of the techniques of EUS and EBUS and their role in the staging of lung cancer patients.
\end{abstract}

Keywords Endo-oesophageal ultrasound $\cdot$ Endobronchial ultrasound · Lung cancer

\section{Introduction}

Lung cancer is still the leading cause of cancer mortality worldwide with a poor overall survival rate. In the diagnosis of lung cancer mediastinal lymph node sampling is important for adequate staging in order to determine appropriate treatment as well as predicting outcome [1]. Apart from that,

M. Schuhmann $\cdot$ R. Eberhardt $\cdot$ F. J. F. Herth

Department of Pneumonology and Critical Care Medicine,

Thoraxklinik at University Hospital Heidelberg,

Amalienstr. 5,

69126 Heidelberg, Germany

M. Schuhmann $(\bowtie)$

Southampton University Hospital Trust,

Southampton, UK

e-mail: mschuhm@hotmail.com adequate staging of lung cancer is also important in order to improve research into lung cancer, for accurate comparison of data and for quality control. Noninvasive radiological staging can aid in the initial assessment of metastatic spread but lymph node sampling will still need to be performed to determine nodal infiltration. Mediastinoscopy used to be the gold standard for nodal sampling, but other techniques such as endobronchial ultrasound and endo-oesophageal ultrasound are playing a bigger role in obtaining tissue samples from mediastinal lymph nodes.

The TNM staging for lung cancer has recently been revised (Table 1), with the downstaging of a number of nodal stations. N0 describes no nodal spread; N1 represents spread to the ipsilateral intrapulmonary, hilar or peribronchial lymph nodes; N2 staging involves ipsilateral or subcarinal mediastinal nodes; N3 status describes contralateral mediastinal or supraclavicular nodes.

For an overview of mediastinal lymph nodes, see Fig. 1 [2]. Lymph node stations $3 \mathrm{a}$ and $\mathrm{b}$ are not demonstrated here as they are visualised only on a lateral view.

\section{Imaging of the mediastinum}

Computed tomography (CT), magnetic resonance imaging (MRI), positron emission tomography (PET) and PET-CT are useful noninvasive imaging techniques for the staging of lung cancer; however, they are not sufficiently sensitive or specific to determine mediastinal lymph node involvement [3-7]. CT is usually the initial method for staging of the mediastinal nodes. According to national and international guidelines, however, only lymph nodes with a short axis diameter over a size of $1 \mathrm{~cm}$ ( \pm positivity in PET if performed as a PET-CT for example) are usually considered to have suspected malignant involvement judged by radiological criteria. 
Table 1 TNM staging table; the new changes are highlighted in grey, adjusted from Detterbeck et al. [2]

\begin{tabular}{|c|c|c|c|c|c|}
\hline$T$ and $M$ & & NO & N1 & N2 & N3 \\
\hline UICC6 and Descriptor & New T/M & Stage & Stage & Stage & Stage \\
\hline $\mathrm{T} 1(<=2 \mathrm{~cm})$ & T1a & IA & IIA & IIIA & IIIB \\
\hline $\mathrm{T} 1(>2-3 \mathrm{~cm})$ & T1b & IA & IIA & IIIA & IIIB \\
\hline T2 $(<5 \mathrm{~cm})$ & T2a & IB & IIA & IIIA & IIIB \\
\hline $\mathrm{T} 2(>5-7 \mathrm{~cm})$ & T2b & IIA & IIB & IIIA & IIIB \\
\hline T2 $(>7 \mathrm{~cm})$ & \multirow{3}{*}{ T3 } & IIB & IIIA & IIIA & IIIB \\
\hline T3 invasion & & IIB & IIIA & IIIA & IIIB \\
\hline T4 (same lobe nodules) & & IIB & IIIA & IIIA & IIIB \\
\hline T4 (extension) & \multirow{2}{*}{ T4 } & IIIA & IIIA & IIIB & IIIB \\
\hline M1 (ipsilateral lung) & & IIIA & IIIA & IIIB & IIIB \\
\hline T4 (pleural effusion) & \multirow{2}{*}{ M1a } & IV & IV & IV & IV \\
\hline M1 (contralateral lung) & & IV & IV & IV & IV \\
\hline M1 (distant) & M1b & IV & IV & IV & IV \\
\hline
\end{tabular}

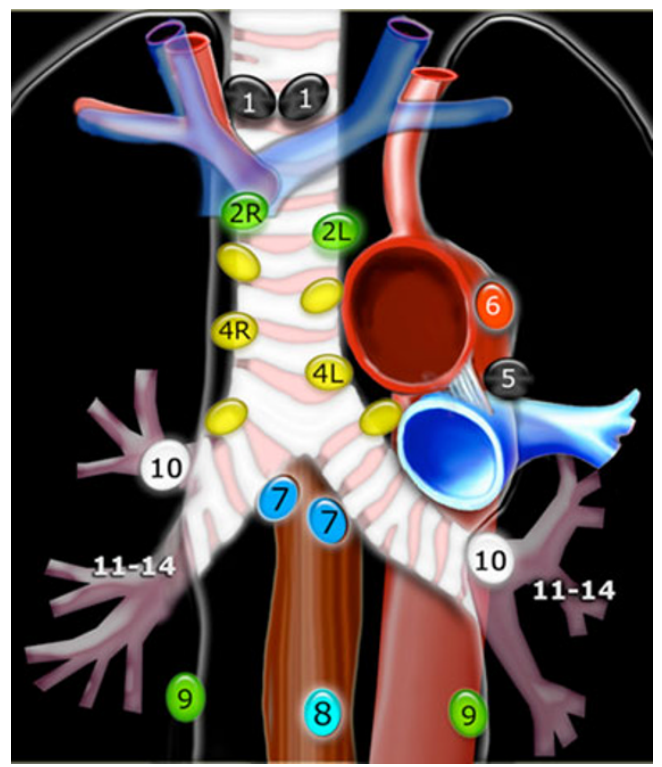

Fig. 1 Lymph node stations in the mediastinum. Lymph node stations $3 \mathrm{a}$ and $\mathrm{b}$ are only visible on side views and not accessible by endobronchial ultrasound (EBUS) or endoscopic ultrasound (EUS)
Integrated $\mathrm{PET} / \mathrm{CT}$ has been reported to be more accurate than PET alone [8]. Given the high false-positive rate in CT and PET-CT [3], however, and the fact that these tests do not provide a tissue diagnosis, it is important to obtain lymph node tissue to determine operability.

Guidelines suggest that positive PET findings within the mediastinum should be confirmed with invasive techniques before any operative procedure [4, 9, 10]. Even when PET is negative, invasive staging ought to be considered if the tumour is central, positive N1 nodes on CT or PET are seen, positive mediastinal nodes on CT are seen or if there is low FDG uptake in the primary tumour [9, 10].

One study comparing PET/CT and endobronchial ultrasound-guided transbronchial needle aspiration (EBUS-TBNA) in lymph node staging showed the diagnostic accuracy of PET/CT to be $62.4 \%$ and that of EBUSTBNA to be $97.4 \%[3,5]$.

Tissue sampling techniques in the mediastinum

Cervical mediastinoscopy has been the gold standard for mediastinal staging for many years and has shown a pooled 
sensitivity in two systematic reviews of $78-81 \%[9,11]$. Only certain lymph node stations are accessible (1, 2, 3, 4 and anterior 7), while access to the posterior and inferior mediastinum is limited and requires extended cervical mediastinoscopy or thoracoscopy. Even with these procedures, it is not possible to evaluate the hilar lymph nodes.

Since mediastinoscopy is an invasive and expensive procedure, requiring general anaesthesia and an operating theatre, less invasive techniques such as endobronchial ultrasound and endo-oesophageal ultrasound have been developed over the last few years.

\section{Endobronchial ultrasound}

Developed in 2002, the EBUS bronchoscope (models Olympus BF-UC160F-OL8 or BF-UC260F-OL8 and Pentax EB-1970 UK) looks similar to a normal bronchovideoscope, and the smallest available diameter is currently $6.3 \mathrm{~mm}$ wide with a 2.2-mm working or instrument channel and a 30-degree side viewing optic. Furthermore, a curved linear array ultrasonic transducer sits on the distal end (Fig. 2) and can be used either with direct contact to the mucosal surface or via an inflatable balloon, which can be attached at the tip. This allows a conventional endoscopic picture side-by-side with the ultrasound view. Ultrasound is performed at a frequency of $7.5-12 \mathrm{MHz}$ with tissue penetration of $20-50 \mathrm{~mm}$. A dedicated ultrasound processor creates the ultrasound image.

Endobronchial ultrasound allows the bronchoscopist to visualise airway structures as well as surrounding tissue. It is very valuable for staging of advanced cancer with regard

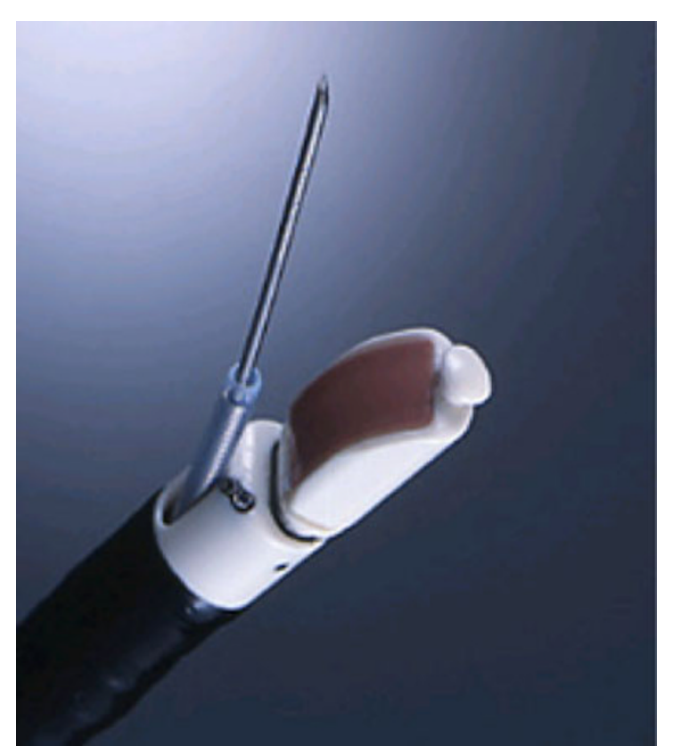

Fig. 2 Distal end of the EBUS Scope. With permission from Olympus, Tokyo, Japan

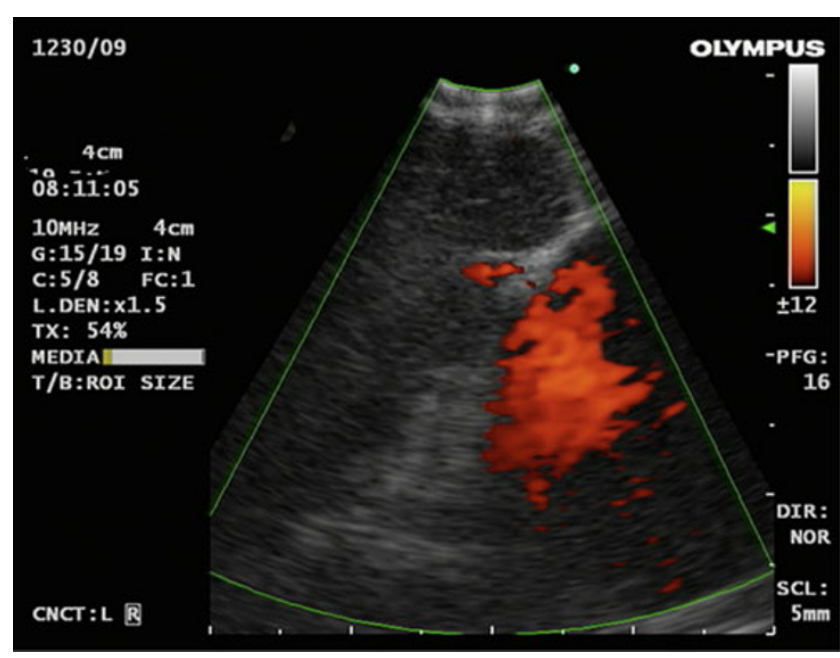

Fig. 3 EBUS image with lymph node and adjacent pulmonary artery in power Doppler mode

to intramural or nodal spread. EBUS can identify N2 and N3 nodes without the need for surgical intervention. An additional advantage is the high resolution of mediastinal structures to show tumour invasion and to diagnose intrapleural tumours. At the same time colour Doppler as well as power Doppler can be used to identify surrounding vascular structures. The images obtained are generally easier to interpret than those of radial endobronchial ultrasound probes (Fig. 3).

Different needles of 21- and 22-gauge are available and can be advanced through the working channel of the EBUS scope (Fig. 4) in order to puncture lymph nodes under realtime ultrasound visualisation. The needle has an internal stylet to avoid contamination with bronchial wall mucosa

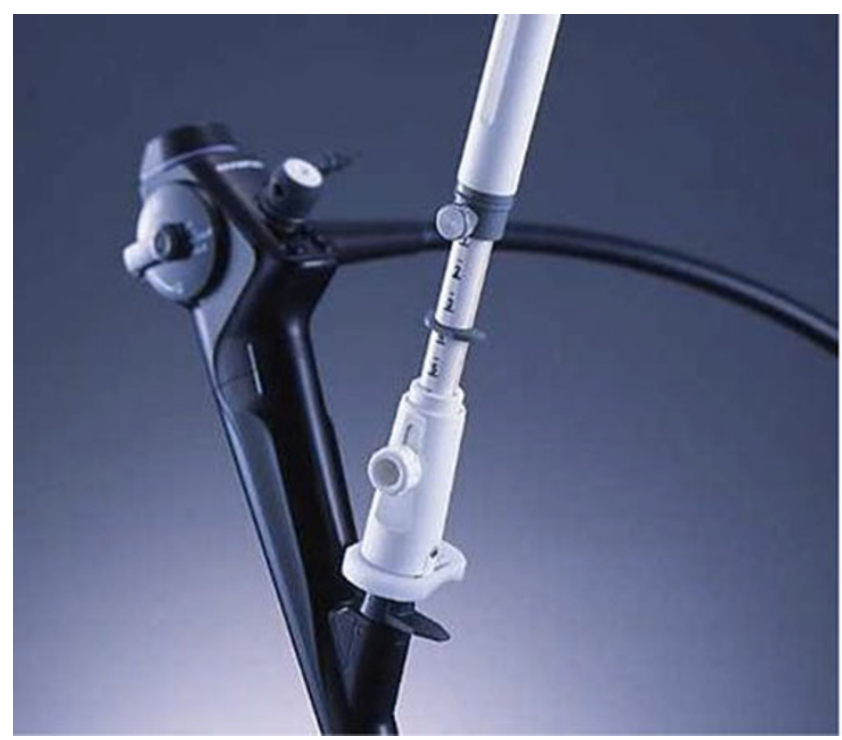

Fig. 4 Olympus EBUS Scope with TBNA (NA-201SX-4022) needle attached 
during biopsy. Biopsies under real-time endosonography control allow for a better yield in comparison to 'blind' needle aspiration (Fig. 5). Ideally three punctures [12] of each lymph node should be performed to achieve an optimal yield.

Lymph node stations that can be reached via EBUS are the highest mediastinal (station 1), upper paratracheal ( $2 \mathrm{~L}$ and $2 \mathrm{R}$ ), lower paratracheal ( $4 \mathrm{R}$ and $4 \mathrm{~L}$ ), subcarinal (station 7), hilar (station 10) as well as interlobar (station 11) and lobar nodes (station 12). It is important to remember that lymph node stations 5, 6, 8 and 9 are not routinely accessible by this method. The highest staging lymph node should be biopsied first; otherwise, the needle requires changing each time to avoid contamination and false-positive results [13].

Lymph nodes at a size of $5 \mathrm{~mm}$ and upwards can be successfully sampled and have to date been proven to have excellent diagnostic yield. The learning curve for EBUSTBNA has been evaluated and recorded at ten supervised procedures in order to achieve excellent sensitivity and diagnostic accuracy [14].

In a recent meta-analysis EBUS-TBNA has been shown to have a high pooled sensitivity of $93 \%$ and specificity of $100 \%$ [15]. Multiple publications provide evidence that even in patients with lymph nodes under $1 \mathrm{~cm}$ (which had been termed N0 by CT criteria), with the use of EBUSTBNA a large percentage could still be shown to have N2/ $\mathrm{N} 3$ disease (some despite also being negative on PET-CT) [16-18].

Complications such as bleeding or infection are very rare and have only been reported as case reports [19-21].

\section{Endo-oesophageal ultrasound}

Gastroenterologists have been using this technique for many years in the investigation of oesophageal and pancreatic malignancies. The linear EUS Scope (Olympus

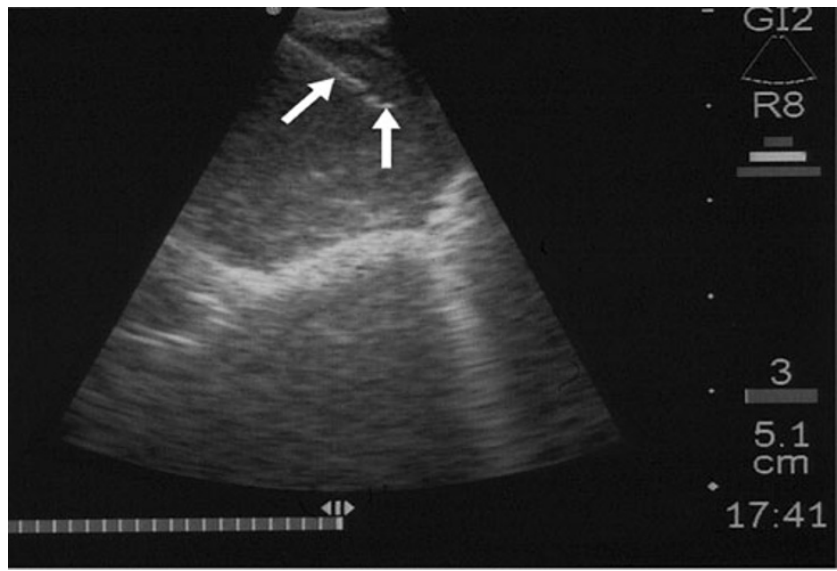

Fig. 5 EBUS needle being advanced into lymph node

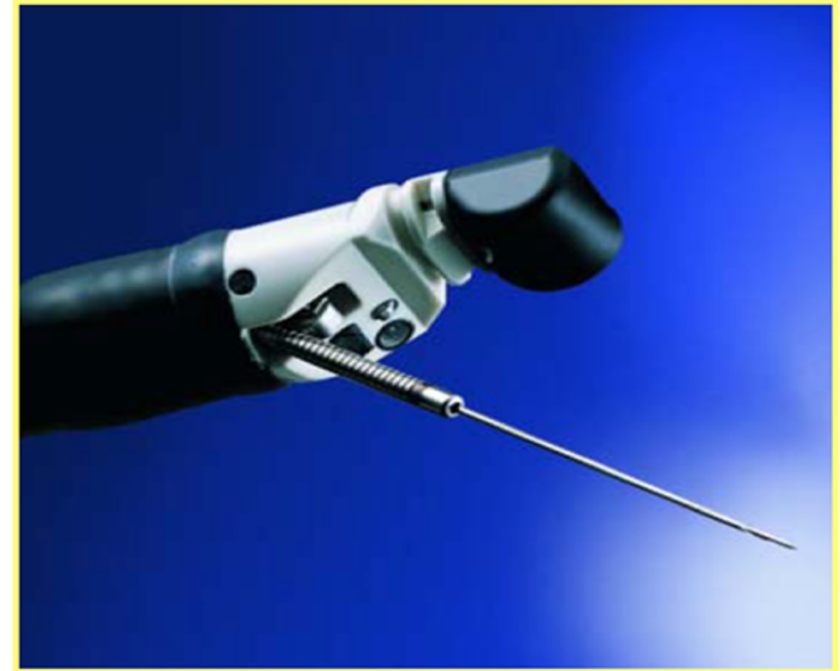

Fig. 6 Distal end of the EUS Scope, with permission from Olympus, Tokyo, Japan

GF-UC160P-OL5/GF-UCT160-OL5 or Pentax EG3830UT) has the same basic architecture as the EBUS scope and uses a device with between 5 and $10 \mathrm{MHz}$ (Fig. 6). The tissue penetration of the ultrasound can be up to $8 \mathrm{~cm}$ (Fig. 7). Endo-oesophageal ultrasound (EUS) is especially useful in the staging of the posterior mediastinum, lymph node station $4 \mathrm{~L}, 7$, lower para-oesophageal (station 8), inferior pulmonary ligament lymph nodes (station 9) and coeliac lymph nodes. Lymph node stations $1 \mathrm{~L}$ and $2 \mathrm{~L}$ can also be reached. The left adrenal can be identified in up to $97 \%$ [22] and has a so-called 'seagull' shape on ultrasound. It is particularly well visualised in cases of metastatic enlargement (Fig. 8). Furthermore, the left lobe of the liver can also be accessed. The hilar and precarinal lymph nodes however cannot be reached, with lymph node stations $2 \mathrm{R}, 3$ and $4 \mathrm{R}$ only poorly accessible by EUS.

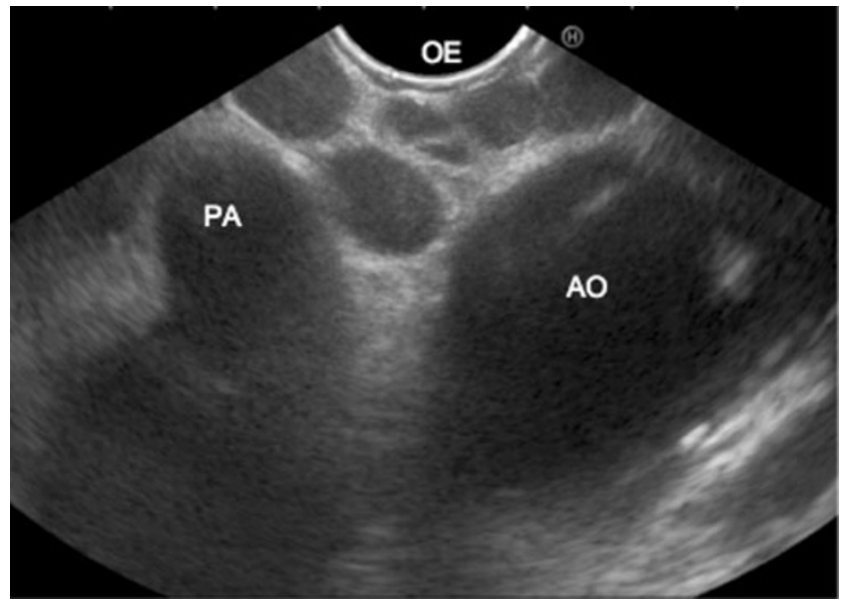

Fig. 7 EUS image. With kind permission from J. Annema. Multiple subcentimeter nodes between oesophagus (OE), aorta (AO) and pulmonary artery (PA). This represents lymph node station 4 left 


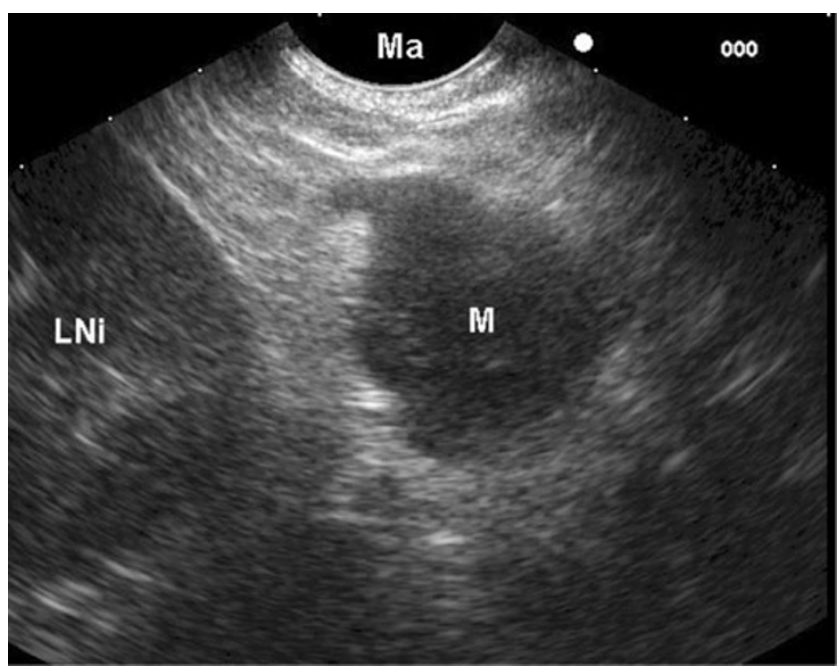

Fig. 8 EUS picture of enlarged left adrenal gland. With kind permission from J. Annema. $\mathrm{Ma}=$ stomach, $\mathrm{M}=$ left adrenal gland, $\mathrm{LNi}=$ left kidney

Needles used for biopsy are 19- or 21-gauge, again equipped with a stylet. Different types of needles are available for EUS, such as Medi-Globe, Olympus and Cook needles. The procedure is usually performed on an outpatient basis and takes approximately $30 \mathrm{~min}$.

As with EBUS, the puncture of lymph nodes is performed under real-time ultrasound guidance.

Endo-oesophageal ultrasound is more accurate and has a higher predictive value than either PET or CT for posterior mediastinal lymph nodes [23], and multiple publications as well as a meta-analysis on endo-oesophageal ultrasound fine-needle aspiration (EUS-FNA) have shown a high sensitivity and specificity [23-25]. Even in patients without mediastinal lymph node enlargement on CT, EUS-FNA has been able to demonstrate metastases in $25 \%$ of lung cancer patients $[16,26]$.

The procedure carries only a very small risk of mediastinitis or bleeding. Unless cysts are punctured, antibiotics do not need to be administered routinely $[27,28]$.

\section{Combining EBUS and EUS}

A comparison of the range of sampling sites between EUSFNA with EBUS-TBNA as shown in Table 2 highlights the fact that EUS and EBUS provide access to different areas of the mediastinum and also differing approaches to nodal stations, and are thought of as complementary procedures. In combining both techniques, most lymph node stations as well as the left adrenal gland can be reached (apart from stations 3, 5 and 6). In six recent series the accuracy of EUS-FNA and EBUS-TBNA used in combination for the diagnosis of mediastinal cancer was 95\% [29-34]. Using
Table 2 Comparison of the range of tissue sampling sites between endo-oesophageal ultrasound fine-needle aspiration (EUS-FNA) and endobronchial ultrasound-guided transbronchial needle aspiration (EBUS-TBNA)

\begin{tabular}{lll}
\hline & EUS & EBUS \\
\hline Mediastinal staging (N2/N3) & ++ & ++ \\
Mediastinal restaging (N2/N3) & + & + \\
Hilar staging (N1/N3) & - & ++ \\
Intrapulmonary tumours (T) & + & + \\
Tumour invasion (T4) (central vessels) & + & $-/+$ \\
Left adrenal gland (M1) & + & - \\
\hline
\end{tabular}

the EBUS scope for both endobronchial as well as endooesophageal sampling, the sensitivity for cancer detection was shown to be as high as $96 \%$ (EUS $89 \%$, EBUS 91), with a specificity of $100 \%$ and negative predictive value of 96\% (EUS 82\%, EBUS 92\%) [33].

Rapid on-site evaluation (ROSE) of the material obtained further increases the yield and has been shown to be cost-effective [35]. A cytopathologist screens the needle aspirates in the endoscopy suite for the presence of diagnostic material, ensuring adequate samples are obtained before ending the procedure. When a positive sample is collected, the procedure can be abandoned, thus avoiding unnecessary multiple punctures of lymph nodes.

It is important to remember however that with EBUS and EUS the negative predictive value is under discussion. The guidelines available $[9,10]$ currently recommend that samples that do not contain tumour cells require follow-up with a more definitive procedure such as mediastinoscopy or video-assisted thoracoscopy (VATS). Recent publications however [33, 34] suggest that the negative predictive value has improved significantly and therefore may no longer be an issue.

\section{Application of endoscopic ultrasound in routine practice}

The main barrier to the routine use of EBUS and EUS in staging lung cancer is the variable procedure reimbursement seen in different countries as well as inconsistent introduction into national or local guidelines.

To date most of these procedures have been performed at centres of excellence, and results on sensitivity and specificity are only available from these centres rather than from routine use at smaller hospitals. Competency in these techniques is becoming more common however, and with this wider practice more consistent utilisation should be possible. The guidelines with regard to how to achieve and maintain competency are currently under discussion. 


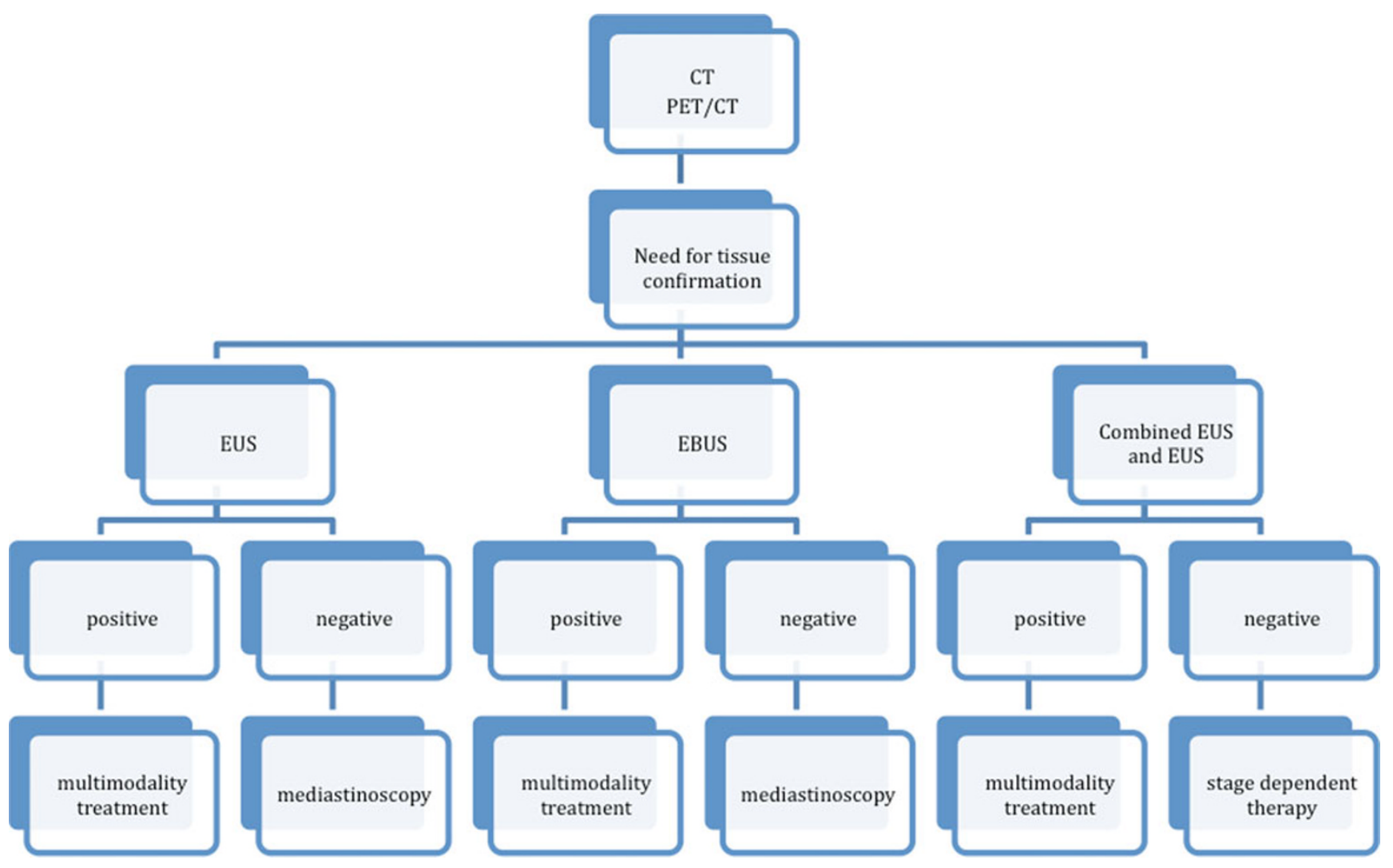

Fig. 9 Proposed decision tree

With the expansion in the use of the technique, it is important to note that the results of the biopsies depend largely on the availability of a trained cytopathologist, which might impede development in some institutions.

As previously mentioned, even though with the combination of both techniques most lymph node stations within the mediastinum can be reached, stations 3, 5 and 6 are not accessible to either technique and may require more invasive staging.

\section{Decision tree for staging the mediastinum}

With different staging techniques in lung cancer available to the physician, we propose a decision tree as shown in Fig. 9. The initial staging procedure should be a CT or PET$\mathrm{CT}$ as both are easily available and noninvasive. If then there is a need for tissue confirmation the procedure should be EUS, EBUS or a combination of both depending on which lymph node stations need to be reached. As per the guidelines the next step should be mediastinoscopy in cases of negative cytology from the lymph node sampling.

\section{Restaging of the mediastinum}

Accurate restaging of the mediastinum is important in patients with stage III disease following induction chemoradiotherapy to consider whether these patients would benefit from surgery. The discussion continues as to which technique ought to be applied to achieve the best sensitivity and specificity $[36,37]$.

Response evaluation of the mediastinum by serial CT after induction therapy can be difficult as gross residual tumour may be present at surgery despite stable disease on CT [38]. The sensitivity and specificity for PET-CT in the
Table 3 Comparison of sensitivity, specificity and accuracy of PET, mediastinoscopy (MES), EUS and EBUS for restaging the mediastinum in lung cancer

\begin{tabular}{llllll}
\hline & & $\mathrm{n}$ & Sensitivity (\%) & Specificity (\%) & Accuracy (\%) \\
\hline PET [44] & 8 trials & 380 & 59 & 85 & \\
MES & 3 trials & 204 & 71 & 100 & 81 \\
EUS [45, 46] & 2 trials & 58 & $70-75$ & $96-100$ & $86-92$ \\
EBUS [47, 48] & 2 trials & 185 & $67-76$ & $86-100$ & $77-80$ \\
\hline
\end{tabular}


evaluation of persistent mediastinal disease are less than in the initial mediastinal lymph node staging [39-41]. However, researchers have recently looked at the percentage change in SUVmax rather than the size of the lymph nodes or lesion, and found that if this decreases by more than $80 \%$ a complete response can be predicted with $96 \%$ accuracy [42]. Repeat mediastinoscopy for restaging is also a valuable tool despite the fact that sensitivity and accuracy are lower than for the first procedure [43].

The value of EBUS-TBNA and EUS-FNA in restaging of the mediastinum was evaluated in four different publications, demonstrating a high sensitivity, specificity and accuracy for these techniques (Table 3).

As mentioned before, the adequate restaging technique remains a matter of debate, as the comparison of the different techniques is still problematic. Endoscopic techniques are safe, minimally invasive and produce accurate results in comparison to surgical data from re-mediastinoscopy. Nevertheless, if needle aspiration is negative, surgical restaging is required to adequately assess the mediastinum before any decision is made to carry out surgery.

\section{Conclusion}

Overall, EBUS and EUS are both safe and effective techniques for the staging of the mediastinum, allowing a reduction in the number of invasive staging procedures.

Previously the main limitations to EBUS and EUS were that they used to be predominantly performed at centres of excellence and hence only on selected patients. Nowadays, though, more and more physicians and surgeons are trained in these techniques. Training remains an issue, and performance of an adequate amount of procedures per year is required in order to maintain competency. Reimbursement for these procedures can pose a further problem in some countries as well as the actual introduction into cancer guidelines within the hospitals.

Increasingly, however, both techniques are being used in hospitals across the world, improving the diagnostic yield. EBUS and EUS ought to be regarded as the first-line techniques for investigating the mediastinum.

\section{References}

1. Sihoe AD, Yim AP (2004) Lung cancer staging. J Surg Res 117:92-106

2. Detterbeck FC, Boffa DJ, Tanoue LT (2009) The new lung cancer staging system. Chest 136:260-271

3. Bauwens O, Dusart M, Pierard P et al (2008) Endobronchial ultrasound and value of PET for prediction of pathological results of mediastinal hot spots in lung cancer patients. Lung Cancer $61: 356-361$
4. Silvestri GA, Gould MK, Margolis ML et al (2007) Noninvasive staging of non-small cell lung cancer: ACCP evidenced-based clinical practice guidelines (2nd edition). Chest 132:178S-201S

5. Hwangbo B, Kim SK, Lee HS et al (2009) Application of endobronchial ultrasound-guided transbronchial needle aspiration following integrated PET/CT in mediastinal staging of potentially operable non-small cell lung cancer. Chest 135:1280-1287

6. Toloza EM, Harpole L, McCrory DC (2003) Noninvasive staging of non-small cell lung cancer: a review of the current evidence. Chest 123:137S-146S

7. Pillot G, Siegel BA, Govindan R (2006) Prognostic value of fluorodeoxyglucose positron emission tomography in non-small cell lung cancer: a review. J Thorac Oncol 1:152-159

8. Gamez C, Rosell R, Fernandez A et al (2006) PET/CT fusion scan in lung cancer: current recommendations and innovations. $\mathrm{J}$ Thorac Oncol 1:74-77

9. Detterbeck FC, Jantz MA, Wallace M et al (2007) Invasive mediastinal staging of lung cancer: ACCP evidence-based clinical practice guidelines (2nd edition). Chest 132:202S-220S

10. De Leyn P, Lardinois D, Van Schil PE et al (2007) ESTS guidelines for preoperative lymph node staging for non-small cell lung cancer. Eur J Cardiothorac Surg 32:1-8

11. Toloza EM, Harpole L, Detterbeck F et al (2003) Invasive staging of non-small cell lung cancer: a review of the current evidence. Chest 123:157S-166S

12. Lee HS, Lee GK, Kim MS et al (2008) Real-time endobronchial ultrasound-guided transbronchial needle aspiration in mediastinal staging of non-small cell lung cancer: how many aspirations per target lymph node station? Chest 134:368-374

13. Tournoy KG, van Meerbeeck JP (2010) The role of EBUS-TBNA for the assessment of hilar lymph nodes. J Thorac Oncol 5:410

14. Groth SS, Whitson BA, D'Cunha J et al (2008) Endobronchial ultrasound-guided fine-needle aspiration of mediastinal lymph nodes: a single institution's early learning curve. Ann Thorac Surg 86:1104-1109, discussion 9-10

15. Gu P, Zhao YZ, Jiang LY et al (2009) Endobronchial ultrasoundguided transbronchial needle aspiration for staging of lung cancer: a systematic review and meta-analysis. Eur J Cancer 45:13891396

16. Wallace MB, Ravenel J, Block MI et al (2004) Endoscopic ultrasound in lung cancer patients with a normal mediastinum on computed tomography. Ann Thorac Surg 77:1763-1768

17. Herth FJ, Eberhardt R, Krasnik M et al (2008) Endobronchial ultrasound-guided transbronchial needle aspiration of lymph nodes in the radiologically and positron emission tomographynormal mediastinum in patients with lung cancer. Chest 133:887891

18. Herth FJ, Ernst A, Eberhardt R et al (2006) Endobronchial ultrasound-guided transbronchial needle aspiration of lymph nodes in the radiologically normal mediastinum. Eur Respir J 28:910-914

19. Haas AR (2009) Infectious complications from full extension endobronchial ultrasound transbronchial needle aspiration. Eur Respir J 33:935-938

20. Steinfort DP, Johnson DF, Irving LB (2010) Incidence of bacteraemia following endobronchial ultrasound-guided transbronchial needle aspiration. Eur Respir J 36:28-32

21. Steinfort DP, Johnson DF, Irving LB (2009) Infective complications from endobronchial ultrasound-transbronchial needle aspiration. Eur Respir J 34:524-525, author reply 5

22. Chang KJ, Erickson RA, Nguyen P (1996) Endoscopic ultrasound (EUS) and EUS-guided fine-needle aspiration of the left adrenal gland. Gastrointest Endosc 44:568-572

23. Singh P, Camazine B, Jadhav Y et al (2007) Endoscopic ultrasound as a first test for diagnosis and staging of lung cancer: a prospective study. Am J Respir Crit Care Med 175:345-354 
24. Eloubeidi MA, Cerfolio RJ, Chen VK et al (2005) Endoscopic ultrasound-guided fine needle aspiration of mediastinal lymph node in patients with suspected lung cancer after positron emission tomography and computed tomography scans. Ann Thorac Surg 79:263-268

25. Micames CG, McCrory DC, Pavey DA et al (2007) Endoscopic ultrasound-guided fine-needle aspiration for non-small cell lung cancer staging: a systematic review and metaanalysis. Chest 131:539-548

26. Fernandez-Esparrach G, Gines A, Belda J et al (2006) Transesophageal ultrasound-guided fine needle aspiration improves mediastinal staging in patients with non-small cell lung cancer and normal mediastinum on computed tomography. Lung Cancer $54: 35-40$

27. Wildi SM, Hoda RS, Fickling W et al (2003) Diagnosis of benign cysts of the mediastinum: the role and risks of EUS and FNA. Gastrointest Endosc 58:362-368

28. Annema JT, Veselic M, Versteegh MI et al (2003) Mediastinitis caused by EUS-FNA of a bronchogenic cyst. Endoscopy 35:791793

29. Herth FJ, Lunn W, Eberhardt R et al (2005) Transbronchial versus transesophageal ultrasound-guided aspiration of enlarged mediastinal lymph nodes. Am J Respir Crit Care Med 171:1164-1167

30. Wallace MB, Pascual JM, Raimondo M et al (2008) Minimally invasive endoscopic staging of suspected lung cancer. JAMA 299:540-546

31. Vilmann P, Krasnik M, Larsen SS et al (2005) Transesophageal endoscopic ultrasound-guided fine-needle aspiration (EUS-FNA) and endobronchial ultrasound-guided transbronchial needle aspiration (EBUS-TBNA) biopsy: a combined approach in the evaluation of mediastinal lesions. Endoscopy 37:833-839

32. Rintoul RC, Skwarski KM, Murchison JT et al (2005) Endobronchial and endoscopic ultrasound-guided real-time fine-needle aspiration for mediastinal staging. Eur Respir J 25:416-421

33. Herth FJ, Krasnik M, Kahn N et al (2010) Combined endoesophageal-endobronchial ultrasound-guided, fine-needle aspiration of mediastinal lymph nodes through a single bronchoscope in 150 patients with suspected lung cancer. Chest 138(4):790-794

34. Hwangbo B, Lee GK, Lee HS, et al. Transbronchial and transesophageal fine needle aspiration using an ultrasound bronchoscope in mediastinal staging of potentially operable lung cancer. Chest 138(4):795-802

35. Baram D, Garcia RB, Richman PS (2005) Impact of rapid on-site cytologic evaluation during transbronchial needle aspiration. Chest 128:869-875

36. Goldstraw P (2006) Selection of patients for surgery after induction chemotherapy for N2 non-small-cell lung cancer. J Clin Oncol 24:3317-3318
37. Robinson LA, Ruckdeschel JC, Wagner H Jr et al (2007) Treatment of non-small cell lung cancer-stage IIIA: ACCP evidence-based clinical practice guidelines (2nd edition). Chest 132:243S-265S

38. Albain KS, Rusch VW, Crowley JJ et al (1995) Concurrent cisplatin/etoposide plus chest radiotherapy followed by surgery for stages IIIA (N2) and IIIB non-small-cell lung cancer: mature results of Southwest Oncology Group phase II study 8805. J Clin Oncol 13:1880-1892

39. De Leyn P, Stroobants S, De Wever W et al (2006) Prospective comparative study of integrated positron emission tomographycomputed tomography scan compared with remediastinoscopy in the assessment of residual mediastinal lymph node disease after induction chemotherapy for mediastinoscopy-proven stage IIIAN2 Non-small-cell lung cancer: a Leuven Lung Cancer Group Study. J Clin Oncol 24:3333-3339

40. Ohtsuka T, Nomori H, Ebihara A et al (2006) FDG-PET imaging for lymph node staging and pathologic tumor response after neoadjuvant treatment of non-small cell lung cancer. Ann Thorac Cardiovasc Surg 12:89-94

41. Ryu JS, Choi NC, Fischman AJ et al (2002) FDG-PET in staging and restaging non-small cell lung cancer after neoadjuvant chemoradiotherapy: correlation with histopathology. Lung Cancer 35:179-187

42. Cerfolio RJ, Bryant AS, Ojha B (2006) Restaging patients with N2 (stage IIIa) non-small cell lung cancer after neoadjuvant chemoradiotherapy: a prospective study. J Thorac Cardiovasc Surg 131:1229-1235

43. Marra A, Hillejan L, Fechner S et al (2008) Remediastinoscopy in restaging of lung cancer after induction therapy. J Thorac Cardiovasc Surg 135:843-849

44. Vansteenkiste J, Dooms C (2007) Positron emission tomography in nonsmall cell lung cancer. Curr Opin Oncol 19:78-83

45. Stigt JA, Oostdijk AH, Timmer PR et al (2009) Comparison of EUS-guided fine needle aspiration and integrated PET-CT in restaging after treatment for locally advanced non-small cell lung cancer. Lung Cancer 66:198-204

46. Annema JT, Veselic M, Versteegh MI et al (2003) Mediastinal restaging: EUS-FNA offers a new perspective. Lung Cancer 42:311-318

47. Herth FJ, Annema JT, Eberhardt R et al (2008) Endobronchial ultrasound with transbronchial needle aspiration for restaging the mediastinum in lung cancer. J Clin Oncol 26:3346-3350

48. Szlubowski A, Herth FJ, Soja J et al (2010) Endobronchial ultrasound-guided needle aspiration in non-small-cell lung cancer restaging verified by the transcervical bilateral extended mediastinal lymphadenectomy - a prospective study. Eur J Cardiothorac Surg 37:1180-1184 